\title{
Association between infection with Campylobacter species, poor oral health and environmental risk factors on esophageal cancer: a hospital-based case-control study in Thailand
}

Arisara Poosari ${ }^{1}$, Thitima Nutravong ${ }^{1 *}$, Prakasit Sa-ngiamwibool ${ }^{2}$, Wises Namwat ${ }^{1}$, Supaporn Chatrchaiwiwatana ${ }^{3}$ and Piti Ungareewittaya ${ }^{2}$

\begin{abstract}
Background: Previous studies have shown the association between Campylobacter species infection and that environmental factors, poor oral hygiene in particular, are linked to an increased risk of esophageal cancer (EC). However, no study has reported on these factors in Thailand. Thus, this study's objective was to evaluate the impact of the relationship between Campylobacter infection and environmental factors on EC incidence in the population of Thailand.

Methods: Data from a case-control study were collected from 105 newly diagnosed EC cases and 105 controls recruited from 2007 to 2017. Infection with Campylobacter spp. was detected in the formalin-fixed paraffin-embedded (FFPE) tissue of EC taken from gastroesophageal biopsy specimens obtained from the participants, and evaluated using TaqMan ${ }^{\circledR}$ real-time PCR. Multivariable logistic regression was performed to calculate the odds ratios (ORs) and perform data analysis.

Results: Smoking, alcohol use, a family history of cancer, history of gastroesophageal reflux disease, poor oral hygiene and Campylobacter spp. infection were shown to be significant risk factors for EC $(p<0.05)$. The combination of poor oral hygiene and infection with Campylobacter spp. constituted significant risk for EC $(p<0.001)$. In addition, the risk of $E C$ in subjects co-infected with $C$. rectus and $C$. concisus that practiced poor oral hygiene was even higher and was significant (ORadj $=4.7 ; 95 \% \mathrm{Cl} 2.41-9.98 ; p=0.003$ ).

Conclusions: In Thailand, the major risk factors for EC are smoking status, alcohol drinking, family history of cancer, GERD, poor oral hygiene and Campylobacter spp. infection. This study found Campylobacter spp. prevalence to be associated with EC and appears to be enhanced by poor oral hygiene, suggesting that a combination of poor oral hygiene and Campylobacter species infection may together act as an important etiological risk factor for EC.
\end{abstract}

Keywords: Campylobacter species, Poor oral hygiene, Risk factor, Esophageal cancer

*Correspondence: thicha@kku.ac.th

${ }^{1}$ Department of Microbiology, Faculty of Medicine, Khon Kaen University, Khon Kaen 40002, Thailand

Full list of author information is available at the end of the article

\section{Introduction}

Esophageal cancer (EC), which primarily affects the upper gastrointestinal tract, is the seventh most common cancer worldwide and a leading cause of death; it was responsible for an estimated 5,08,585 cancer deaths original author(s) and the source, provide a link to the Creative Commons licence, and indicate if changes were made. The images or other third party material in this article are included in the article's Creative Commons licence, unless indicated otherwise in a credit line to the material. If material is not included in the article's Creative Commons licence and your intended use is not permitted by statutory regulation or exceeds the permitted use, you will need to obtain permission directly from the copyright holder. To view a copy of this licence, visit http://creativecommons.org/licenses/by/4.0/. The Creative Commons Public Domain Dedication waiver (http://creativeco mmons.org/publicdomain/zero/1.0/) applies to the data made available in this article, unless otherwise stated in a credit line to the data. 
(5\% of all cancer deaths) in 2018 [1]. An increase in new cases is reported annually [2]. The etiology of EC is multifactorial and involves various factors, such as the host, environment and infectious agents [3-5]. Previous studies have reported that key environmental risk factors for EC incidence include smoking, alcohol consumption, gastroesophageal reflux disease (GERD), a family history of cancer, poor oral hygiene and Campylobacter spp. infection, but the causes of EC vary from country to country [6-15]. Numerous studies have found that cigarette smoking and alcohol consumption are significant risk factors for EC (50 times greater than that of individuals who neither drink nor smoke) [16, 17]. Epidemiological evidence has shown that bacterial infections are associated with cancer and EC etiology [18-20]. Recently, researchers established that Campylobacter spp., characterized by oral upper digestive tract microbiota, is a major cause of foodborne bacterial infections in developed and developing countries worldwide [21, 22]. Campylobacter spp., highly motile, spiral-shaped Gram-negative bacteria, are increasingly being identified as an upper gastrointestinal tract pathogen and subsequent premalignant lesions of the esophagus and prolonged diarrhea, having previously been primarily associated with colonization of the digestive system [23, 24]. The epidemiology of symptomatic Campylobacter spp. infection in humans reflects the complexity and variability of Campylobacter sources. Common and major causes of Campylobacter infection include the consumption of undercooked meat, contaminated drinking water, unpasteurized dairy products and direct contact with farm animals [25-27]. Modern researchers have focused on characterizing bacterial communities and identifying differences in healthy and diseased states globally [28]. Various studies have revealed that infection with Gramnegative bacteria in the presence of esophageal abnormalities, such as Barrett's esophagus, plays a vital role in the pathogenesis of inflammation and metaplasia [29, 30]. Recently, significant microbial diversity was demonstrated in esophageal squamous cell carcinoma (ESCC), esophagogastric junction (EGJ) cancer and post-ESCC groups, compared to the healthy control group, with the most significant differences observed between the ESCC and healthy control group participants, in particular using microbial composition analysis. Thus, monitoring the esophageal microbiota may be a useful method of predicting the recurrence of tumor [31]. In one study, Campylobacter was shown to colonize the esophagus of most patients with Barrett's esophagus and was linked to enteritis, periodontal infection and tumor formation; however, it was not identified in the control group [32]. It has been proposed that infection with C. concisus is a risk factor for the development of Barrett's esophagus (BE), a condition that is needed for the development of EC [33]. By contrast, a reversed trend was reported in one study, with a low rate of Campylobacter spp. identified in the control and cancer patients, together with a high prevalence of GERD and BE [34]. Therefore, there is a significant gap in knowledge regarding microbial influences on EC, with insufficient data available in the literature. Only a few studies have prospectively analyzed the impact of upper digestive tract microbiota on EC risk. Therefore, the primary objective of the current case-control study was to determine the prevalence of Campylobacter spp. in EC tissue using gastroesophageal biopsy specimens obtained from the participants using real-time PCR. A secondary objective was to assess the impact of the combination of Campylobacter spp. infection and environmental factors including oral hygiene on EC incidence in the population of northeastern Thailand.

\section{Material and methods}

\section{Study design and participants}

This study involved a hospital-based case-control study of patients admitted to Srinagarind Hospital in the city of Khon Kaen, Northeast Thailand. Case and control specimens were obtained retrospectively from the Pathology Department at Srinagarind Hospital from 2007 to 2017. One hundred and five patients with EC and 105 healthy controls were recruited in this hospital-based case-control study, approved by the Khon Kaen University Ethics Committee for Human Research (HE621269).

The control group patients were admitted with esophagitis at the same time as the cancer cases. The cases and controls were recruited from Srinagarind Hospital in Khon Kaen province, Northeast Thailand, from 2007 to 2017. Data collection was conducted by trained nurses. The EC cases comprised new patients whose diagnosis was clinically and histologically confirmed according to the International Classification of Diseases for Oncology, 3rd Edition (ICD-O-3) codes: C15.3, C15.4, C15.5, C15.8, C15.9 and C16.0. The histological diagnosis was reviewed in each case and confirmed by two pathologists, and the medical reports were obtained from the Pathology Department.

The control subjects were healthy individuals, confirmed upon physical examination, who underwent clinical and biochemical analysis during the same period that the cases group were recruited. Eligible controls included individuals without a history of gastric or esophageal malignancy. The subjects were randomly sampled from patients undergoing routine endoscopy for investigation of presumed nonmalignant conditions, such as GERD. A criterion was that their esophageal biopsies had to be macroscopically normal in appearance. The participants 
provided written informed consent to participate in the current study.

Data on the subjects were obtained using an interviewer-based structured questionnaire. Prior to data collection, trained staff served as interviewers to ensure the validity of the questionnaire questions. The demographic information sought included age, gender, height, weight, smoking status, alcohol consumption, a family history of cancer, oral hygiene practices and a history of GERD. Data on cigarette smoking included the age that smoking started, the number of cigarettes smoked per day and smoking duration. A smoker was defined as a current smoker who smoked at least one cigarette per day, having done so for at least 6 months. Alcohol consumption was divided into two groups (drinkers and non-drinkers). Drinking status was defined as drinking alcohol at least once a day for at least 6 months; non-drinkers were those who consumed alcohol less than once a month. Detailed information was obtained on the participants' oral hygiene practices, for example, the daily frequency with which they brushed their teeth (never, less than once a day, twice or more per day), the type of instrument used to clean their teeth, the regularity of dental visits (never, annually and every $2-5$ years) and a previous history of gingivitis or periodontal disease.

\section{Tissue samples}

Formalin-fixed paraffin-embedded (FFPE) samples $[N=$ $210 ; n=105 \mathrm{EC}$ samples (case group) and $n=105$ normal tissue samples (control group)] were collected retrospectively between 2007 and 2017 and retrieved from paraffin blocks stored at the Department of Pathology, Faculty of Medicine, Khon Kaen University. Esophageal squamous cell carcinoma (ESCC) and esophageal adenocarcinoma samples were categorized in the case group, and normal esophageal tissue samples were assigned to the control group. The samples were initially evaluated by a specialist; thereafter, the diagnoses were confirmed using electronic gastroscopy, a histopathology report and ICD-O-3 guidance.

\section{Laboratory methods}

\section{DNA extraction and quality control}

DNA was extracted from the FFPE tissue. The FFPE esophageal tissue was cut into $10-\mu \mathrm{M}$ sections placed in a 1.5 microcentrifuge tube. Eight sections from each sample were used for DNA extraction. Prior to sectioning, the microtomes and accessories were cleaned using $70 \%$ ethanol alcohol. The DNA of the FFPE tissue samples was extracted using a commercially available system, DNeasy ${ }^{\circledR}$ Blood \& Tissue Kits (Qiagen, Hilden, Germany), according to the manufacturer's instructions. Briefly, eight sections (10 $\mu \mathrm{M}$ each) from each FFPE tissue specimen were deparaffinized in xylene and 95\% ethanol. The deparaffinized tissue was washed twice with 95\% ethanol; $1000 \mu \mathrm{l}$ of ethanol was added and vortexed for $30 \mathrm{~s}$ and then centrifuged at 13,000 rpm for $5 \mathrm{~min}$. The tissue pellets were then washed with distilled water and air dried. The recommended protocols for DNA FFPE extraction were followed (Qiagen, DNA FFPE Tissue ${ }^{\circledR}$, Germany). The yields and quality of the DNA isolated during the process were determined using a NanoDrop ${ }^{\circledR}$ ND-1000 Spectrophotometer (Thermo Scientific, Wilmington, USA). The housekeeping gene ( $\beta$-actin) served as an endogenous control to guarantee the DNA quality and was detected using a specific primer (forward 5'-TGTCACAGTGCAAGCTCACTCAGT-3', reverse $5^{\prime}$-TCCTGAGGAGAAGTCTGCCGTT- $3^{\prime}$ ), following the protocols described elsewhere [35]. The integrity of the extracted DNA samples was confirmed by amplifying the housekeeping gene ( $\beta$-actin) using SYBR Green-based real-time polymerase chain reaction (real-time PCR). The DNA samples were stored at $-20^{\circ} \mathrm{C}$ for further analysis.

\section{Campylobacter species detection using a TaqMan ${ }^{\circledR}$ real-time PCR assay}

To detect Campylobacter infection, a TaqMan ${ }^{\circledR}$ real-time PCR detection system, which utilizes fluorogenic-labeled probes, was used to determine the infection agent count [36]. Specific TaqMan ${ }^{\circledR}$ PCR primers and fluorescently labeled probes (Additional file 1: Table S1) were designed using the Oligoware ${ }^{\circledR} 1.0$ software program (Integrated DNA Technology, Coralville, USA). Thereafter, theoretical testing was conducted on the candidate primers and probes, and sequence comparisons were made using the BLAST database (National Institutes of Health, USA). For each infectious agent tested, the TaqMan ${ }^{\circledR}$ PCR assay was performed (a final volume of $20 \mu \mathrm{l}$ for the PCR reaction). Each reaction comprised $1 \times$ THUNDERBIRD $^{\mathrm{TM}}$ qPCR Mix (Toyobo Co. Ltd., Japan), $10 \mu \mathrm{l}$ of TaqMan ${ }^{\circledR}$ qPCR Mix, $0.3 \mu \mathrm{M}$ of each forward and reverse primer, $0.2 \mu \mathrm{M}$ of TaqMan ${ }^{\circledR}$ probe and $50 \mathrm{ng}$ of DNA template. The amplification, data acquisition and Campylobacter genus DNA analysis were carried out using an Applied Biosystems ${ }^{\circledR} 7500$ flats system.

PCR amplification comprised an initial denaturation cycle at $95{ }^{\circ} \mathrm{C}$ for $5 \mathrm{~min}$, followed by 40 amplification cycles at $95{ }^{\circ} \mathrm{C}$ for $30 \mathrm{~s}$, annealing at $55{ }^{\circ} \mathrm{C}$ for $22 \mathrm{~s}$ and final extension at $72{ }^{\circ} \mathrm{C}$ for $30 \mathrm{~s}$. The Campylobacter spp. cycling conditions were as follows: initial denaturation with $5 \mathrm{~min}$ at $95{ }^{\circ} \mathrm{C}$, followed by 40 amplification cycles at $95^{\circ} \mathrm{C}$ for $30 \mathrm{~s}$, a specific Tm set for each primer for $30 \mathrm{~s}$ and final extension at $72{ }^{\circ} \mathrm{C}$ for $30 \mathrm{~s}$. DNA was extracted from three strains following sequencing of the $16 \mathrm{~S}$ rRNA genes and used as the positive control as in Table 1, and molecular distilled water was used as the negative 
Table 1 Demographic characteristics of the esophageal cancer cases and controls

\begin{tabular}{|c|c|c|c|c|c|}
\hline \multirow[t]{2}{*}{ Characteristics } & \multicolumn{2}{|l|}{ Cases } & \multicolumn{2}{|l|}{ Controls } & \multirow[t]{2}{*}{$p$ value } \\
\hline & $\mathrm{N}=105$ & & $\mathrm{~N}=105$ & & \\
\hline \multicolumn{6}{|l|}{ Gender } \\
\hline Female & 42 & $(40.0 \%)$ & 56 & $(53.3 \%)$ & $0.053^{\mathrm{a}}$ \\
\hline Male & 63 & (60.0\%) & 49 & $(46.7 \%)$ & \\
\hline Age (mean \pm SD) & $59.5 \pm 8.7$ & & $56.7 \pm 13.2$ & & $0.012^{\mathrm{t}}$ \\
\hline \multicolumn{6}{|l|}{ Drinking status } \\
\hline Non-drinker & 33 & (31.4\%) & 64 & $(61.0 \%)$ & $<0.001^{\circ}$ \\
\hline Drinker & 72 & $(68.6 \%)$ & 41 & (39.0\%) & \\
\hline \multicolumn{6}{|l|}{ Smoking status } \\
\hline Non-smoker & 45 & $(48.2 \%)$ & 72 & $(68.6 \%)$ & $<0.001^{\mathrm{a}}$ \\
\hline Smoker & 60 & (51.8\%) & 33 & $(31.4 \%)$ & \\
\hline $\begin{array}{l}\text { Body mass index; BMI }\left(\mathrm{kg} / \mathrm{m}^{2}\right) \\
\quad(\text { mean } \pm \mathrm{SD})\end{array}$ & $24.1 \pm 3.62$ & $23.4 \pm 3.46$ & & & $0.490^{k}$ \\
\hline$<23.00$ & 49 & $(46.7 \%)$ & 54 & $(51.4 \%)$ & \\
\hline$\geq 23.00$ & 56 & $(53.3 \%)$ & 51 & $(48.6 \%)$ & \\
\hline Marital status & & & & & $0.964^{2}$ \\
\hline Single & 9 & $(8.6 \%)$ & 9 & $(8.6 \%)$ & \\
\hline Married & 88 & (83.8\%) & 89 & $(84.8 \%)$ & \\
\hline Separated & 8 & $(7.6 \%)$ & 7 & $(6.7 \%)$ & \\
\hline \multicolumn{6}{|c|}{ Family history of cancer in first-degree relatives } \\
\hline No & 27 & $(25.7 \%)$ & 60 & $(57.1 \%)$ & $<0.001^{\circ}$ \\
\hline Yes & 78 & $(74.3 \%)$ & 45 & $(42.9 \%)$ & \\
\hline \multicolumn{6}{|c|}{ Personal history of gastroesophageal reflux disease } \\
\hline No & 25 & $(23.8 \%)$ & 65 & $(61.9 \%)$ & $<0.001^{\circ}$ \\
\hline Yes & 80 & $(76.2 \%)$ & 40 & $(38.1 \%)$ & \\
\hline \multicolumn{6}{|l|}{ Poor oral hygiene } \\
\hline No & 33 & $(31.4 \%)$ & 55 & $(52.4 \%)$ & $0.002^{2}$ \\
\hline Yes & 72 & $(68.6 \%)$ & 50 & $(47.6 \%)$ & \\
\hline \multicolumn{6}{|l|}{ Campylobacter genus infection } \\
\hline Negative & 44 & $(41.9 \%)$ & 80 & $(76.2 \%)$ & $<0.001^{\mathrm{a}}$ \\
\hline Positive & 61 & (58.1\%) & 25 & (23.8\%) & \\
\hline
\end{tabular}

${ }^{a} p$ value differences between cases and controls were detected using the Chi-squared test

${ }^{\mathrm{b}} p$ value differences between cases and controls were detected using the Wilcoxon rank-sum test

control. Both were utilized in each PCR assay run. The samples and controls were tested in duplicate, and those considered positive were replicated following amplification within a cycle of $<36$.

\section{Statistical analysis}

The demographic characteristics of the subjects were summarized using descriptive statistics. The categorical data were expressed using frequencies and percentages, and the continuous data, such as the age of the subjects, were depicted by mean \pm standard deviation (SD), median, and minimum and maximum range. Bivariate analysis was performed using simple logistic regression to determine the association between the independent factors and EC, without controlling for confounding variables. The crude odds ratio ( $\left.\mathrm{OR}_{\text {crude }}\right)$ and the $95 \%$ confidence interval $(95 \% \mathrm{CI})$ were also calculated. Multivariable unconditional logistic regression was used to compute adjusted odds ratios (ORadj) and their 95\% confidence intervals (95\% CI) for the association between EC risk factors and EC, while controlling for the effects of confounding variables. Candidate variables for the multivariable analysis were selected according to two criteria: firstly, variables in the crude analysis which were found to have a $p$ value of less than 0.25 , and secondly, variables shown from a literature review to have an association with esophageal cancer. The method of backward stepwise elimination was used as the model fitting 
strategy. A likelihood ratio test was performed to assess the goodness-of-fit of the final model. The test statistics were two-sided, and a $p$ value less than 0.05 was considered statistically significant. The statistical analysis was performed using Stata ${ }^{\circledR}$ software (version 13.0).

\section{Results}

\section{Demographic characteristics}

The characteristics of the $105 \mathrm{EC}$ cases and 105 controls are provided in Table 1 . The gender and age distribution differed between the cases and controls (men, 60\% and $47 \%$, respectively; women, 40 and $53 \%$, respectively). The mean age $( \pm \mathrm{SD})$ of the men and women was 59.5 years $( \pm 8.7)$ and 56.7 years $( \pm 13.2)$, respectively. The demographics of the subjects' lifestyle habits were evaluated.
Drinking status, smoking and poor oral hygiene were more prevalent among the cases than the controls. The frequency of a family history of cancer and a personal history of GERD differed between the cases and controls $(p<0.05)$. Campylobacter spp. infection was identified in 61 cases (58\%) and 25 controls (24\%).

\section{Risk factors for esophageal cancer}

The primary outcomes of the multivariable analysis are depicted in Table 2. Factors found to be significantly associated with EC were alcohol consumption, smoking status, a family history of cancer in a first-degree relative, a personal history of GERD and poor oral hygiene. The dose-response relationship between poor oral hygiene and EC risk was statistically significant $(p<0.05)$. Poor

Table 2 Crude and adjusted odds ratios for the association of esophageal cancer and various risk factors

\begin{tabular}{|c|c|c|c|c|c|c|c|}
\hline \multirow[t]{2}{*}{ Variables } & \multicolumn{2}{|l|}{ Cases } & \multicolumn{2}{|l|}{ Control } & \multirow[t]{2}{*}{$\mathrm{OR}_{\mathrm{C}}(95 \% \mathrm{Cl})$} & \multirow[t]{2}{*}{$\mathrm{OR}_{\mathrm{adj}}(95 \% \mathrm{Cl})$} & \multirow[t]{2}{*}{$p$ value } \\
\hline & $N=105$ & & $N=105$ & & & & \\
\hline Gender & & & & & & & 0.261 \\
\hline Female & 42 & $(40.0 \%)$ & 56 & $(53.3 \%)$ & 1.0 (reference) & 1.0 (reference) & \\
\hline Male & 63 & $(60.0 \%)$ & 49 & $(46.7 \%)$ & $1.7(0.98-2.96)$ & $1.3(0.77-2.53)$ & \\
\hline Age (years) & & & & & & & 0.339 \\
\hline$<60$ & 14 & $(13.3 \%)$ & 35 & $(33.4 \%)$ & 1.0 (reference) & 1.0 (reference) & \\
\hline$\geq 60$ & 91 & $(86.7 \%)$ & 70 & $(66.6 \%)$ & $1.8(0.99-3.01)$ & $1.4(0.71-2.81)$ & \\
\hline Body mass index; BMI $\left(\mathrm{kg} / \mathrm{m}^{2}\right)$ & & & & & & & 0.912 \\
\hline$<23.00$ & 49 & $(46.7 \%)$ & 54 & $(51.4 \%)$ & 1.00 (reference) & 1.00 (reference) & \\
\hline$\geq 23.00$ & 56 & $(53.3 \%)$ & 51 & $(48.6 \%)$ & $1.21(0.71-2.08)$ & $1.03(0.55-1.95)$ & \\
\hline Marital status & & & & & & & 0.810 \\
\hline Single & 9 & $(8.6 \%)$ & 9 & $(8.6 \%)$ & 1.00 (reference) & 1.00 (reference) & \\
\hline Married & 88 & $(83.8 \%)$ & 89 & $(84.8 \%)$ & $0.98(0.37-2.61)$ & $0.01(0.35-2.93)$ & \\
\hline Separated & 8 & $(7.6 \%)$ & 7 & $(6.7 \%)$ & $1.14(0.28-4.21)$ & $1.11(0.26-5.63)$ & \\
\hline Drinking status & & & & & & & 0.016 \\
\hline Non-drinker & 33 & (31.4\%) & 64 & $(61.0 \%)$ & 1.0 (reference) & 1.0 (reference) & \\
\hline Drinker & 72 & $(68.6 \%)$ & 41 & $(39.0 \%)$ & $3.4(1.93-6.02)$ & $3.2(1.25-8.62)$ & \\
\hline Smoking status & & & & & & & 0.015 \\
\hline Non-smoker & 45 & $(48.2 \%)$ & 72 & $(68.6 \%)$ & 1.0 (reference) & 1.0 (reference) & \\
\hline Smoker & 60 & $(51.8 \%)$ & 33 & $(31.4 \%)$ & $3.3(1.86-5.77)$ & $3.5(1.28-9.56)$ & \\
\hline $\begin{array}{l}\text { Family history of cancer in first- } \\
\text { degree relatives }\end{array}$ & & & & & & & 0.001 \\
\hline No & 27 & $(25.7 \%)$ & 60 & $(57.1 \%)$ & 1.0 (reference) & 1.0 (reference) & \\
\hline Yes & 78 & $(74.3 \%)$ & 45 & $(42.9 \%)$ & $3.8(2.15-6.91)$ & $3.7(1.69-8.12)$ & \\
\hline $\begin{array}{l}\text { Personal history of gastro esopha- } \\
\text { gus reflux diseases (GERD) }\end{array}$ & & & & & & & 0.008 \\
\hline No & 25 & $(23.8 \%)$ & 65 & $(61.9 \%)$ & 1.0 (reference) & 1.0 (reference) & \\
\hline Yes & 80 & $(76.2 \%)$ & 40 & $(38.1 \%)$ & $4.2(2.86-9.44)$ & $2.8(1.29-5.62)$ & \\
\hline Poor oral hygiene & & & & & & & $<0.001$ \\
\hline No & 33 & $(31.4 \%)$ & 55 & $(52.4 \%)$ & 1.0 (reference) & 1.0 (reference) & \\
\hline Yes & 72 & $(68.6 \%)$ & 50 & (47.6\%) & $2.8(1.36-4.21)$ & $3.0(1.44-6.26)$ & \\
\hline
\end{tabular}

$p$ value from unconditional logistic regression

ORc crude odds ratio; ORadj adjusted odds ratio; 95\% CI 95\% confidence interval 
oral hygiene increased the odds of developing EC by $49 \%$ $\left(\mathrm{OR}_{\mathrm{adj}}=3.0 ; 95 \%\right.$ CI 1.44-6.26; $\left.p<0.001\right)$.

\section{Campylobacter species infection}

The results of Campylobacter spp. infection relative to EC are detailed in Table 3. Campylobacter infection was associated with an increased risk of $\mathrm{EC}$, and this finding was statistically significant $\left(\mathrm{OR}_{\mathrm{adj}}=4.8 ; 95 \% \mathrm{CI}\right.$ $2.26-10.04 ; p<0.001)$. C. concisus and C. rectus were also significantly associated with EC $(p<0.001)$. In addition, subjects who were co-infected with $C$. rectus and $C$. concisus were at increased odds ratio of EC, and the association between this risk factor and EC was statistically significant $\left(\mathrm{OR}_{\mathrm{adj}}=3.4,95 \%\right.$ CI 1.34-6.61; $\left.p=0.002\right)$.

\section{A combination of poor oral hygiene and Campylobacter species infection}

The impact of the combination of poor oral hygiene and infection with Campylobacter spp. as a risk factor for EC was found to be statistically significant at $p<0.001$ (Table 4). The association between EC and poor oral hygiene in combination with $C$. concisus infection was significantly greater than that between $\mathrm{EC}$ and poor oral hygiene in combination with $C$. rectus $\left(\mathrm{OR}_{\mathrm{adj}}=4.2 ; 95 \%\right.$ CI 1.88-9.47; $p<0.001 ; \mathrm{OR}_{\text {adj }}=3.1,95 \%$ CI 1.33-7.38; $p=0.008$, respectively). The risk of EC was slightly higher in subjects who were co-infected with $C$. rectus and $C$. concisus and who practiced poor oral hygiene (an increased OR), and the risk associated with these combined factors was statistically significant $\left(\mathrm{OR}_{\mathrm{adj}}=4.7\right.$; 95\% CI 2.41-9.98; $p<0.003$ ).

\section{Discussion}

The objective of the current study was to evaluate the relationship between environmental risk factors, in particular microbial factors, and their association with the incidence of EC. In Thailand, the major risk factors for esophageal cancer appear to be smoking status, alcohol drinking, a family history of cancer in a first-degree relative, a personal history of GERD, poor oral hygiene and Campylobacter spp. infection. Our results suggest that, in this multifactorial cancer, Campylobacter spp. may well be a risk factor. This study found Campylobacter spp. prevalence is associated with EC and seems to be enhanced by poor oral hygiene, suggesting that a combination of poor oral hygiene and Campylobacter species infection may together act as an important etiological risk factor for EC. The association between Campylobacter spp. and EC is inconclusive based on current findings in the literature, and the prevalence of Campylobacter

Table 3 The relationship between Campylobacter species and esophageal cancer risk

\begin{tabular}{|c|c|c|c|c|c|c|c|}
\hline \multirow[t]{2}{*}{ Variables } & \multicolumn{2}{|c|}{ Cases } & \multicolumn{2}{|c|}{ Controls } & \multirow[t]{2}{*}{$\mathrm{OR}_{\mathrm{C}}(95 \% \mathrm{Cl})$} & \multirow[t]{2}{*}{$\mathrm{OR}_{\mathrm{adj}}(95 \% \mathrm{Cl})$} & \multirow[t]{2}{*}{$p$ value } \\
\hline & \multicolumn{2}{|c|}{$N=105$} & \multicolumn{2}{|c|}{$N=105$} & & & \\
\hline \multicolumn{8}{|l|}{ Gender } \\
\hline Female & 42 & $(40.0 \%)$ & 56 & (53.3\%) & 1.0 (reference) & 1.0 (reference) & 0.261 \\
\hline Male & 63 & $(60.0 \%)$ & 49 & $(46.7 \%)$ & $1.7(0.98-2.96)$ & $1.3(0.77-2.53)$ & \\
\hline \multicolumn{8}{|l|}{ Age (years) } \\
\hline$<60$ & 14 & $(13.3 \%)$ & 35 & $(33.4 \%)$ & 1.0 (reference) & 1.0 (reference) & 0.339 \\
\hline$\geq 60$ & 91 & $(86.7 \%)$ & 70 & $(66.6 \%)$ & $1.8(0.99-3.01)$ & $1.4(0.71-2.81)$ & \\
\hline \multicolumn{8}{|c|}{ Campylobacter species infection } \\
\hline Negative & 44 & $(41.9 \%)$ & 80 & $(76.2 \%)$ & 1.0 (reference) & 1.0 (reference) & $<0.001$ \\
\hline Positive & 61 & $(58.1 \%)$ & 25 & $(23.8 \%)$ & $4.4(2.45-8.03)$ & $4.8(2.26-10.04)$ & \\
\hline \multicolumn{8}{|c|}{ Type of Campylobacter species infection } \\
\hline \multicolumn{8}{|c|}{ Campylobacter rectus infection } \\
\hline Negative & 70 & $(66.7 \%)$ & 90 & $(85.7 \%)$ & 1.0 (reference) & 1.0 (reference) & 0.027 \\
\hline Positive & 35 & $(33.3 \%)$ & 15 & $(14.3 \%)$ & $3.3(2.25-8.37)$ & $2.8(1.11-6.10)$ & \\
\hline \multicolumn{8}{|c|}{ Campylobacter concisus infection } \\
\hline Negative & 59 & $(56.2 \%)$ & 87 & $(84.8 \%)$ & 1.0 (reference) & 1.0 (reference) & 0.004 \\
\hline Positive & 46 & $(43.8 \%)$ & 18 & $(15.2 \%)$ & $3.0(1.52-5.93)$ & $3.1(1.42-6.77)$ & \\
\hline \multicolumn{8}{|l|}{ Co-infection } \\
\hline Negative & 74 & $(70.4 \%)$ & 95 & $90.0 \%$ & 1.0 (reference) & 1.0 (reference) & 0.002 \\
\hline Positive & 31 & $(29.6 \%)$ & 10 & $(10.0 \%)$ & $3.8(1.83-8.63)$ & $3.4(1.34-6.61)$ & \\
\hline
\end{tabular}

Co-infection with Campylobacter rectus and Campylobacter concisus

$p$ values obtained using unconditional logistic regression

ORc crude odds ratio; ORadj adjusted odd ratio; 95\% Cl 95\% confidence interval 
Table 4 The relationship between poor oral hygiene behavior and Campylobacter species infection as a risk factor for esophageal cancer

\begin{tabular}{|c|c|c|c|c|c|c|}
\hline \multirow[t]{2}{*}{ Variables } & \multicolumn{2}{|c|}{ Cases } & \multicolumn{2}{|c|}{ Controls } & \multirow[t]{2}{*}{$\mathrm{OR}_{\mathrm{adj}}(95 \% \mathrm{Cl})$} & \multirow[t]{2}{*}{$P$ value } \\
\hline & \multicolumn{2}{|c|}{$N=105$} & \multicolumn{2}{|c|}{$N=105$} & & \\
\hline \multicolumn{7}{|c|}{ Campylobacter spp. infection plus poor oral hygiene } \\
\hline Negative & 62 & $(59.1 \%)$ & 90 & (85.7\%) & 1.0 (reference) & $<0.001$ \\
\hline Positive & 43 & $(40.9 \%)$ & 15 & $(14.3 \%)$ & $4.4(2.31-9.81)$ & \\
\hline \multicolumn{7}{|c|}{ Type of Campylobacter species infection } \\
\hline \multicolumn{7}{|c|}{ Campylobacter rectus infection plus poor oral hygiene } \\
\hline Negative & 81 & $(77.1 \%)$ & 96 & (91.4\%) & 1.0 (reference) & 0.008 \\
\hline Positive & 24 & $(22.9 \%)$ & 9 & $(8.6 \%)$ & $3.1(1.33-7.38)$ & \\
\hline \multicolumn{7}{|c|}{ Campylobacter concisus infection plus poor oral hygiene } \\
\hline Negative & 73 & $(69.5 \%)$ & 95 & (90.4\%) & 1.0 (reference) & $<0.001$ \\
\hline Positive & 32 & $(30.5 \%)$ & 10 & $(9.6 \%)$ & $4.2(1.88-9.47)$ & \\
\hline \multicolumn{7}{|c|}{ Co-infection plus poor oral hygiene } \\
\hline Negative & 69 & $(65.7 \%)$ & 98 & (93.3\%) & 1.0 (reference) & 0.003 \\
\hline Positive & 36 & $(34.2 \%)$ & 7 & $(6.7 \%)$ & $4.7(2.41-9.98)$ & \\
\hline
\end{tabular}

Co-infection with Campylobacter rectus and Campylobacter concisus

$p$ values were obtained using unconditional logistic regression and were adjusted for gender and age

ORadj adjusted odds ratio; 95\% Cl 95\% confidence interval

spp. in patients with EC has not yet been reported in Thailand.

Thus, a case-control study was conducted to identify Campylobacter spp. DNA in the esophageal tissue obtained from patients with EC, and compare it with that of the controls using PCR. The identification of Campylobacter spp. was confirmed using TaqMan ${ }^{\circledR}$ real-time PCR. The prevalence of Campylobacter spp. in the esophageal tissue of 105 cases and 105 controls was 58 and $24 \%$, respectively. In the current study, EC was identified more frequently in men than in women. Similar results have been reported in South Thailand [37]. By contrast, a higher incidence of EC in women, compared to men, has been described in Europe [38]. In the current study, the mean age of the EC patients was 59.5 years, which is similar to that of the EC population (a mean age of 57.8 years) recorded using a cancer registry in Khon Kaen, Thailand [39]. Therefore, it was assumed that the finding in the current research on EC cases was representative of this disease in northeast Thailand. This is one of a few studies that has evaluated the relationship between Campylobacter spp. and $\mathrm{OC}$ by evaluating esophageal tumor tissue specimens.

The prevalence of Campylobacter spp. was assessed in archived FFPE tissue derived from EC cases diagnosed between 2007 and 2017. A large proportion (41\%) of Campylobacter spp. DNA was identified in the tumor specimens, which demonstrated that Campylobacter spp. infection was associated with EC progression, and Campylobacter infection increased EC risk, and this finding was statistically significant $\left(\mathrm{OR}_{\mathrm{adj}}=4.8 ; 95 \% \mathrm{CI}\right.$ 2.26-10.04; $p<0.001$ ).

Similarly, C. concisus and C. rectus were significantly associated with EC $(p<0.001)$. In addition, the risk of EC increased in subjects who were co-infected with $C$. rectus and $C$. concisus and this finding had statistical significance $\left(\mathrm{OR}_{\mathrm{adj}}=3.4 ; 95 \%\right.$ CI 1.34-6.61; $\left.p=0.002\right)$. Specifically, the findings in the current study provided evidence of an association between a combination of poor oral hygiene and Campylobacter spp. infection and EC risk. In general, $C$. rectus and C. concisus are associated with poor oral health, including periodontal disease. A prior population-based study identified an association between poor oral health-periodontal disease and orodigestive cancer due to mono- or polymicrobial infection, which resulted in an increase in proinflammatory cytokines, such as interleukin (IL)-1 $\beta$, IL-6, IL-8 and tumor necrosis factor alpha (TNF $\alpha$ ), ultimately inducing gene expression relating to cell proliferation, for example, oncogenes [40]. It has been shown that $C$. concisus favors colonization in patients with GERD and Barrett's esophagus (i.e., an increased bacterial count) accompanied by a significant decrease in bacterial count for all other genera [41]. Campylobacter spp. was also identified to a greater extent in the biopsy samples of EC cases compared to those in the control group [42]. C. concisus was shown to induce IL-18, TNF $\alpha$ and p53 expression in Barrett's esophageal cell lines. An in vitro study indicated the relationship between esophageal colonization by $C$. concisus and the epithelial production of TNF $\alpha$ and IL-18, known 
to induce both an innate and adaptive immune response and to increase CDX1 and COX-2 expression. In turn, this escalates the rate of colonization and chronic inflammation, which has been shown to lead to disease progression in GERD, Barrett's esophagus and EC [33, 43].

Thus, the findings in the current study provide evidence of a significant association between a combination of poor oral hygiene-Campylobacter spp. infection and EC risk. Similarly, smoking status, alcohol use, a family history of cancer in a first-degree relative and a personal history of GERD were associated with EC in our sample; the magnitude of these effects was strong enough to achieve statistical significance. Therefore, our results may have policy implications for population-based education and awareness throughout Thailand; however, it will be necessary to confirm these findings using a larger sample size and an experimental design that facilitates an evaluation of the mechanistic pathways that link oral hygiene and EC before serious consideration can be given to implementing interventions.

Limitations and bias should be taken into consideration. A main limitation concerns the retrospective crosssectional nature of the case-control design; accordingly, a cause-effect relationship between poor oral health and Campylobacter spp. infection and EC risk could be established. Firstly, recall bias is usually a limitation in casecontrol studies, although using patients as controls may have been beneficial in limiting this bias. The behavior data of risk factors assessment were made based on an interviewer-based structured questionnaire, which probably introduced some recall error in the response of participants. Face-to-face interviews were thus conducted in the presence of kin to help improve the accuracy of their answers. Furthermore, information bias and recall bias were unlikely, because all participants were blind to the study hypothesis. Secondly, the control subjects were selected from patients with esophagitis undergoing routine investigations based on a presumption of nonmalignancy and good health. Nonetheless, disease misclassification was possible because some of the control subjects may have subsequently been diagnosed with EC because, typically, it is slow-growing and remains clinically 'silent' until the late stages.

This study had three important strengths. Firstly, it was a hospital-based case-control study that recruited 105 patients with newly diagnosed EC (the diagnoses were confirmed following clinical and histological analyses after a review of each sample by two pathologists in the Department of Pathology at the Faculty of Medicine, Khon Kaen University) and 105 healthy controls. Secondly, this is the first published study to describe the relationship between poor oral hygiene-infection with Campylobacter spp. and EC in human subjects.
In addition, the study demonstrated a dose-response relationship between poor oral hygiene-infection with Campylobacter spp. and EC risk, which is sound evidence of an underlying causal relationship. Thirdly, the data collection was conducted by trained nurses, the laboratory that evaluated Campylobacter spp. infection used realtime PCR (TaqMan ${ }^{\circledR}$ probes), and unconditional logistic regression was employed for the data analysis.

In conclusion, in this study the factors of alcohol consumption, smoking status, a family history of cancer in a first-degree relative, a personal history of GERD, poor oral hygiene and Campylobacter spp. infection were established to be significant risk factors for EC in Thailand. In addition, the prevalence of Campylobacter spp. in EC cases was significantly higher than that in the controls. Therefore, a combination of poor oral hygiene and infection with Campylobacter spp. were a significant risk factor for EC. Subjects who were co-infected with both C. rectus and C. concisus and characterized by poor oral hygiene behavior were at increased risk of esophageal cancer, and this finding had statistical significance, which suggests that a combination of Campylobacter spp. infection and poor oral health is a potential and significant risk factor for EC. Hence, further prospective cohort studies and studies that utilize larger sample sizes are warranted to confirm the present study's findings, and establish the possible mechanisms for Campylobacter spp. etiology and virulence gene infection in EC.

\section{Abbreviations \\ ${ }^{\circ} \mathrm{C}$ : Celsius; 95\% Cl: 95\% Confidence interval; DNA: Deoxyribonucleic acid; OR adj: Adjusted odds ratios; OR c: Crude odds ratios; TaqMan ${ }^{\circledR}$ real-time PCR: Polymerase chain reaction; SD: Standard deviation; FAM: 6-Carboxyfluorescein- labeled reporter dye; HEX: 7-Hexachloro-6-carboxy-fluorescein-labeled reporter dye; TAMRA: 6-Carboxytetramethyl-rhodamine-labeled quencher dye.}

\section{Supplementary Information}

The online version contains supplementary material available at https://doi. org/10.1186/s40001-021-00561-3.

Additional file 1: Table S1. The detection of bacteria using polymerase chain reaction primers and TaqMan ${ }^{\circledR}$ probes.

\section{Acknowledgements}

The authors would like to thank Professor Dr. Viraphong Lulitanond and research staff, Research and Diagnostic Center for Emerging Infectious Diseases (RCEID), for their helpful technical support. We thank the Department of Epidemiology and Biostatistics, Faculty of Public Health, Khon Kaen University for their contributions to data management and statistical support. We would like to acknowledge Professor lan Thomas for English editing the manuscript via KKU.

\section{Authors' contributions}

Conceived and designed the experiments: AP, TN, WN and PS. Collected FFPE esophageal cancer: PU, PS and AP. Performed the experiments and reviewed statistical analysis of the data: AP, TN and SC. Wrote the manuscript: AP and TN. All of the authors read and approved the final manuscript. 


\section{Funding}

This work was financially supported by the Faculty of Medicine, Khon Kaen University, Thailand (Grant No. IN62314).

\section{Availability of data and materials}

The datasets during and/or analyzed during the current study are available from the corresponding author on reasonable request.

\section{Declarations}

\section{Ethics approval and consent to participate}

This present study was approved by the Khon Kaen University Ethics Committee for Human Research, based on the Declaration of Helsinki and the ICH Good Clinical Practice Guidelines; Reference Number HE621269.

\section{Consent for publication}

Not applicable.

\section{Competing interests}

All authors declare that they have no competing interests.

\section{Author details}

${ }^{1}$ Department of Microbiology, Faculty of Medicine, Khon Kaen University, Khon Kaen 40002, Thailand. ${ }^{2}$ Department of Pathology, Faculty of Medicine, Khon Kaen Universtity, Khon Kaen 40002, Thailand. ${ }^{3}$ Department of Oral Biology, Faculty of Dentistry, Khon Kaen University, Khon Kaen 40002, Thailand.

Received: 20 May 2021 Accepted: 23 July 2021

Published online: 31 July 2021

\section{References}

1. Ferlay J, Colombet M, Soerjomataram I, Mathers C, Parkin DM, Piñeros $M$, et al. Estimating the global cancer incidence and mortality in 2018: GLOBOCAN sources and methods. Int J Cancer. 2019;144(8):1941-53.

2. Bray F, Ferlay J, Soerjomataram I, Siegel RL, Torre LA, Jemal A. Global cancer statistics 2018: GLOBOCAN estimates of incidence and mortality worldwide for 36 cancers in 185 countries. CA Cancer J Clin. 2018;68(6):394-424.

3. Kamangar F, Chow WH, Abnet CC, Dawsey SM. Environmental causes of esophageal cancer. Gastroenterol Clin North Am. 2009;38(1):27-vii.

4. Schneider JL, Corley DA. A review of the epidemiology of Barrett's oesophagus and oesophageal adenocarcinoma. Best Pract Res Clin Gastroenterol. 2015;29(1):29-39.

5. Lee YL, Hu HY, Yang NP, Chou P, Chu D. Dental prophylaxis decreases the risk of esophageal cancer in males; a nationwide population-based study in Taiwan. PLoS ONE. 2015;9(10):e109444.

6. Lepage C, Drouillard A, Jouve J-L, Faivre J. Epidemiology and risk factors for esophageal adenocarcinoma. Dig Liver Dis. 2013;45(8):625-9.

7. Coleman HG, Xie SH, Lagergren J. The epidemiology of esophageal adenocarcinoma. Gastroenterology. 2018;154(2):390-405.

8. Jiang $X$, Tseng CC, Bernstein L, Wu AH. Family history of cancer and gastroesophageal disorders and risk of esophageal and gastric adenocarcinomas: a case-control study. BMC Cancer. 2014;14:60.

9. Rustgi AK, El-Serag HB. Esophageal carcinoma. N Engl J Med. 2014;371(26):2499-509.

10. Bhat S, Coleman HG, Yousef F, Johnston BT, McManus DT, Gavin AT, et al. Risk of malignant progression in Barrett's esophagus patients: results from a large population-based study. J Nat Cancer Inst. 2011;103(13):1049-57.

11. Abnet CC, Kamangar F, Islami F, Nasrollahzadeh D, Brennan P, Aghcheli $K$, et al. Tooth loss and lack of regular oral hygiene are associated with higher risk of esophageal squamous cell carcinoma. Cancer Epidemiol Biomark Prev Publ Am Assoc Cancer Res Cosponsored Am Soc Prev Oncol. 2008;17(11):3062-8.

12. Chen X, Winckler B, Lu M, Cheng H, Yuan Z, Yang Y, et al. Oral microbiota and risk for esophageal squamous cell carcinoma in a high-risk area of China. PLoS ONE. 2015;10(12):e0143603.
13. Ahn J, Sinha R, Pei Z, Dominianni C, Wu J, Shi J, Goedert J, et al. Human gut microbiome and risk for colorectal cancer. J Natl Cancer Inst. 2013;105(24):1907-11.

14. Baba Y, Iwatsuki M, Yoshida N, Watanabe M, Baba H. Review of the gut microbiome and esophageal cancer: pathogenesis and potential clinical implications. Ann Gastroenterol Surg. 2017;1(2):99-104.

15. Akutko K, Matusiewicz K. Campylobacter concisus as the etiologic agent of gastrointestinal diseases. Adv Clin Exp Med Off Organ Wrocl Med Univ. 2017;26(1):149-54.

16. Vioque J, Barber X, Bolumar F, Porta M, Santibáñez M, de la Hera MG, et al. Esophageal cancer risk by type of alcohol drinking and smoking: a casecontrol study in Spain. BMC Cancer. 2008;8:221.

17. Yang X, Chen X, Zhuang M, Yuan Z, Nie S, Lu M, et al. Smoking and alcohol drinking in relation to the risk of esophageal squamous cell carcinoma: a population-based case-control study in China. Sci Rep. 2017;7(1):17249.

18. Leon ME, Kassa E, Bane A, Gemechu T, Tilahun Y, Endalafer N, et al. Prevalence of human papillomavirus and Helicobacter pylori in esophageal and gastroesophageal junction cancer biopsies from a case-control study in Ethiopia. Infect Agents Cancer. 2019. https://doi.org/10.1186/ s13027-019-0233-x.

19. Snider EJ, Freedberg DE, Abrams JA. Potential role of the microbiome in Barrett's esophagus and esophageal adenocarcinoma. Dig Dis Sci. 2016;61(8):2217-25.

20. Elsalem L, Jum'ah AA, Alfaqih MA, Aloudat O. The bacterial microbiota of gastrointestinal cancers: role in cancer pathogenesis and therapeutic perspectives. Clin Exp Gastroenterol. 2020;13:151-85.

21. Peters BA, Wu J, Pei Z, Yang L, Purdue MP, Freedman ND, et al. Oral microbiome composition reflects prospective risk for esophageal cancers. Cancer Res. 2017;77(23):6777-87.

22. Ngobese B, Zishiri OT, El Zowalaty ME. Molecular detection of virulence genes in Campylobacter species isolated from livestock production systems in South Africa. J Integr Agric. 2019. https://doi.org/10.1016/ S2095-3119(19)62844-3.

23. Yang L, Francois F, Pei Z. Molecular pathways: pathogenesis and clinical implications of microbiome alteration in esophagitis and Barrett esophagus. Clin Cancer Res Off J Am Assoc Cancer Res. 2012;18(8):2138-44.

24. Samosornsuk W, Asakura M, Yoshida E, Taguchi T, Nishimura K, Eampokalap B, et al. Evaluation of a cytolethal distending toxin (cdt) gene-based species-specific multiplex PCR assay for the identification of Campylobacter strains isolated from poultry in Thailand. Microbiol Immunol. 2007;51(9):909-17.

25. Carrique-Mas JJ, Bryant JE, Cuong NV, Hoang NV, Campbell J, Hoang $\mathrm{NV}$, et al. An epidemiological investigation of Campylobacter in pig and poultry farms in the Mekong delta of Vietnam. Epidemiol Infect. 2014;142(7):1425-36.

26. Rosner BM, Schielke A, Didelot X, Kops F, Breidenbach J, Willrich N, et al. A combined case-control and molecular source attribution study of human Campylobacter infections in Germany, 2011-2014. Sci Rep. 2017;7(1):5139.

27. García-Sánchez L, Melero B, Rovira J. Campylobacter in the food chain. Adv Food Nutr Res. 2018;86:215-52.

28. Snider EJ, Compres G, Freedberg DE, Khiabanian H, Nobel YR, Stump $S$, et al. Alterations to the oesophageal microbiome associated with progression from Barrett's esophagus to esophageal adenocarcinoma. Cancer Epidemiol Biomarkers Prev. 2019;28(10):1687-93.

29. Amir I, Konikoff FM, Oppenheim M, Gophna U, Half EE. Gastric microbiota is altered in oesophagitis and Barrett's oesophagus and further modified by proton pump inhibitors. Environ Microbiol. 2014;16(9):2905-14.

30. Peter S, Pendergraft A, VanDerPol W, Wilcox CM, Kyanam Kabir Baig KR, Morrow C, et al. Mucosa-associated microbiota in Barrett's esophagus, dysplasia, and esophageal adenocarcinoma differ similarly compared with healthy controls. Clin Transl Gastroenterol. 2020;11(8):e00199.

31. Li D, He R, Hou G, Ming W, Fan T, Chen L, et al. Characterization of the esophageal microbiota and prediction of the metabolic pathways involved in esophageal cancer. Front Cell Infect Microbiol. 2020;10:268.

32. Macfarlane S, Furrie E, Macfarlane GT, Dillon JF. Microbial colonization of the upper gastrointestinal tract in patients with Barrett's esophagus. Clini Infect Dis Off Publ Infect Dis Soc Am. 2007;45(1):29-38.

33. Mozaffari Namin B, Soltan Dallal MM, Ebrahimi Daryani N. The effect of Campylobacter concisus on expression of IL-18, TNF-a and p53 in Barrett's cell lines. Jundishapur J Microbiol. 2015;8(12):6393. 
34. Lv J, Guo L, Liu JJ, Zhao HP, Zhang J, Wang JH. Alteration of the esophageal microbiota in Barrett's esophagus and esophageal adenocarcinoma. World J Gastroenterol. 2019;25(18):2149-61.

35. Samareh-Fekri M, Hashemi Bajgani SM, Shafahi A, Asadi-Zarandi M, Mollaie $H$, Jamali Paghalhe A. Detection of helicobacter pylori in the bronchoalveolar lavage of patients with lung cancer using real-time PCR. Jundishapur J Microbiol. 2016;9(11):2144

36. Saygun I, Kubar A, Sahin S, Sener K, Slots J. Quantitative analysis of association between herpesviruses and bacterial pathogens in periodontitis. J Periodontal Res. 2018;43(3):352-9.

37. Boonyaphiphat $\mathrm{P}$, Thongsuksai $\mathrm{P}$, Sriplung H, Puttawibul P. Lifestyle habits and genetic susceptibility and the risk of esophageal cancer in the Thai population. Cancer Lett. 2002;186(2):193-9.

38. Löfdahl HE, LuY, Lagergren J. Sex-specific risk factor profile in oesophageal adenocarcinoma. Br J Cancer. 2008;99(9):1506-10.

39. Virani S, Bilheem S, Chansaard W, Chitapanarux I, Daoprasert K, Khuanchana S, et al. National and subnational population-based incidence of cancer in Thailand: assessing cancers with the highest burdens. Cancers. 2017;9(8):108
40. Hoare A, Soto C, Rojas-Celis V, Bravo D. Chronic inflammation as a link between periodontitis and carcinogenesis. Mediat Inflamm. 2019. https:// doi.org/10.1155/2019/1029857

41. Blackett KL, Siddhi SS, Cleary S, Steed H, Miller MH, Macfarlane S, et al. Oesophageal bacterial biofilm changes in gastro-oesophageal reflux disease, Barrett's and oesophageal carcinoma: association or causality? Aliment Pharmacol Ther. 2013;37(11):1084-92.

42. Elliott D, Walker AW, O'Donovan M, Parkhill J, Fitzgerald RC. A nonendoscopic device to sample the oesophageal microbiota: a case-control study. Lancet Gastroenterol Hepatol. 2017;2(1):32-42.

43. Mozaffari Namin B, Soltan Dallal MM. Campylobacter concisus and its effect on the expression of CDX1 and COX2. Asian Pac J Cancer Prev APJCP. 2018;19(11):3211-6.

\section{Publisher's Note}

Springer Nature remains neutral with regard to jurisdictional claims in published maps and institutional affiliations.
Ready to submit your research? Choose BMC and benefit from:

- fast, convenient online submission

- thorough peer review by experienced researchers in your field

- rapid publication on acceptance

- support for research data, including large and complex data types

- gold Open Access which fosters wider collaboration and increased citations

- maximum visibility for your research: over $100 \mathrm{M}$ website views per year

At BMC, research is always in progress.

Learn more biomedcentral.com/submissions 